\title{
The Golden Hello and Political Transitions*
}

\author{
Toke S. Aidt ${ }^{\dagger}$ Facundo Albornoz ${ }^{\ddagger}$ and Martin Gassebner ${ }^{\S}$
}

March 2017

\begin{abstract}
We analyze the influence of IMF and World Bank programs on political regime transitions. We develop an extended version of Acemoglu and Robinson's [American Economic Review 91, 2001] model of political transitions to show how the anticipation of new loans from international financial institutions can trigger political transitions which would not otherwise have taken place. We test this unexplored implication of the theory empirically. We find that the anticipation of receiving new loan programs immediately after a political regime transition increases the probability of a transition from autocracy to democracy and reduces the probability of democratic survival.
\end{abstract}

JEL classification: O19, D72, F59, F53.

Keywords: Political transitions; democracy; autocracy; IMF; World Bank.

\section{Introduction}

Political regime transitions are often followed by new loan agreements with international financial institutions, such as the World Bank and the International Monetary Fund (the IMF), or by a surge in foreign development aid. This is true for newly established

${ }^{*}$ We would like to thank participants at the European Public Choice Society Meeting in Izmir, at the PEIO conference in New York, at the 5th Annual CEDI conference on development and institutions at Brunel University, and at the BBQ workshop at Aarhus Business School for helpful comments and suggestions. We also thank Suresh Naidu for sharing data with us and Sourafel Girma for his suggestions.

${ }^{\dagger}$ Faculty of Economics and Jesus College, University of Cambridge, U.K.; CESifo, Munich; toke.aidt@econ.cam.ac.uk.

${ }^{\ddagger}$ School of Economics, University of Nottingham, U.K. and IIEP-CONICET; facundo.albornoz@nottingham.ac.uk.

$\S$ University of Hanover, Germany; CESifo, Munich; gassebner@kof .ethz.ch. 
democracies as well as for newly established autocracies or dictatorships. IMF agreements with newly established democracies include Spain in 1978 and Turkey in 1979, while agreements with newly established dictatorships include Chile in 1974 and Argentina in 1976. Alesina and Dollar (2000) document that in 44 of the 59 democratization episodes they study, the country experienced a significant increase in foreign development aid immediately after the transition. Kalyvitis and Vlachaki (2012) find that aid reduces the prevalence of democracy but stress that the effect depends on underlying economic factors. We refer to valuable resource flows from abroad of this kind in the aftermath of a regime transition as a "golden hello" and investigate the effect of such "welcome gifts" on political regime stability. In essence, we ask if golden hellos induce regime stability or if they, in fact, are a source of political instability.

This investigation allows us to conduct a novel empirical test of Acemoglu and Robinson's theory of political transitions. In a series of papers and a subsequent book, Acemoglu and Robinson have developed a powerful framework in which to analyze the economic origins of dictatorship and democracy (Acemoglu and Robinson 2000, 2001, 2005). ${ }^{1}$ This work has become a major reference point in the field of political economics. Criticisms have mainly focused on the difficulty of testing the theory systematically. Among other things, the political regime type emerging in equilibrium depends on how costly it is to mount coups and revolutions and on whether the threat of a coup or a revolution is credible or not. Obviously, these variables are difficult to quantify and this makes formal testing of the theory hard. ${ }^{2}$

Our test of the theory explores that (plausibly exogenous) variation across time and space in the anticipation of receiving a golden hello after a successful transition affects the likelihood of such political transitions. To make the logic behind the proposed test clear, we extend the theory of political transitions developed by Acemoglu and Robinson (2001) to take into account that after a transition to either democracy or to autocracy (after a coup), the newly established political regime may receive a one-off transfer from abroad (a golden hello). We show that the anticipation of a golden hello causes regime instability. The reason is that the golden hello, on the one hand, increases the value of a transition to democracy. This makes a governing elite, faced with a real and serious threat of revolution, more willing to introduce some form of democracy. On the other hand, once democracy is established, the anticipation of a golden hello enhances the incentive

\footnotetext{
${ }^{1}$ The work has inspired many other studies, including Ellis and Fender (2011) and Dorsch and Maarek (2015).

${ }^{2}$ Przeworski (2009), Aidt and Jensen (2014) and Aidt and Franck (2015) attempt to overcoming this difficulty. They do so by quantifying the threat of revolution and find that this threat was a major cause of transitions from autocracy to democracy during the 19th can 20th century. Burke and Leigh (2010), Brückner and Ciccone (2011) and Aidt and Leon (2016) establish a link between (negative) rainfall shock and democratic change which is also consistent with Acemoglu and Robinson's theory.
} 
of the elite, now in opposition, to mount a coup to get back to autocracy. Clarifying this logic is important because one of the stated intentions behind IMF and World Bank agreements with newly established political regimes is to foster political stability, not to cause instability. Of course, the golden hello could play a more benign role if used selectively to induce democratization. But before we can draw such policy conclusions, the consequences and the importance of the golden hello must be established empirically.

To this end, we use a world sample covering the period from 1970 to 2002 to quantify the effect of the golden hello on the probability of political regime transitions forth and back between democracy and autocracy. Empirically, we define a golden hello as a transfers of resources within two years after a regime transition from either the International Monetary Fund (IMF) or the World Bank. Specifically, we consider new IMF Structural Adjustment (SAF) and Growth Facility agreements and Poverty Reduction and Growth Facilities (PRGF) ${ }^{3}$ with the IMF, or new structural adjustment loans from the World Bank. These programs are important examples of golden hellos because they involve significant new resources made available to a new political regime immediately after the transition and are valuable to the receiving country. Theoretically, however, what matters for the incentive to overthrow or reform an existing political regime is the expectation that a golden hello will be triggered by the regime transition. To quantify this, we assume adaptive expectations and build indicators based on a country's own past record of golden hellos as well as indicators based on the past experience of a country's neighbors. Neighbor effects are plausibly exogenous to the political process of a particular country and, therefore, they reduce the risk of endogeneity bias.

Our analysis is related to multiple strands of the literature and several open questions. In addition to the work by Acemoglu and Robinson discussed above, we contribute to the broader literature on the origins of political institutions (e.g., Boix (2003); Lizzeri and Persico (2004); Gradstein (2007); Congleton (2007); and Congleton (2011)). This literature mainly focuses on domestic factors, such as inequality, growth volatility, and economic development, as the main drivers of political transitions. Some authors have put some emphasis on international factors and the role of the international community. Acemoglu and Robinson (2005, Chapter 10) and López-Córdova and Meissner (2008), for example, argue that international trade and globalization can be a cause of regime transitions, in particular towards democracy. According to Boix (2003, Chapter 1), international capital mobility reduces the scope for redistribution under democracy which, in turn, facilitates democratization. Aidt and Albornoz (2011) show that foreign countries may have an economic interest in sponsoring coups, stabilizing dictatorships and facilitating limited democratization abroad in order to protect their foreign direct invest-

\footnotetext{
${ }^{3}$ The PRGF has been replaced by the Extended Credit Facility after the end of our sample period.
} 
ment. ${ }^{4}$ Bonfatti (2017) emphasizes the strength of economic ties between domestic and foreign groups in a related theory of foreign intervention. ${ }^{5}$ We contribute to this research agenda by showing that international financial institutions influence the regime dynamics observed around the world by "rewarding" newly established political regimes with a golden hello.

The empirical literature on the origins of democracy and autocracy is large and varied. In an extreme bounds analysis, Gassebner et al. (2013) find that, of among 59 factors considered in the literature to explain political regime transitions, past transition is one of the most robust determinant of the establishment and consolidation of democracy. Notably, GDP per capita only influences the survival probability of democracy but not its emergence. To our knowledge, no previous study has investigated theoretically or empirically the effects of transfers to newly established political regimes from international financial institutions. We complement the previous research effort by showing that the "golden hello effect" is real and important.

Our analysis is also related to a vast literature on the influence of international financial institutions on a range of economic and political outcomes. Of particular relevance is the literature on the influence of the IMF and the World Bank on political outcomes. ${ }^{6}$ Barro and Lee (2005) argue that IMF loans have a negative effect on the development of democratic institutions in the recipient countries. This "anti-democratic" effect is consistent with the golden hello. Here, we provide a theoretical reason why IMF loans can have this (unintended) effect and a refined test that focuses on the effect of new IMF loans on regime instability within a well-defined time window. As such, our work speaks directly to the fact that IMF programs affect the "survival rates" of political leaders (Smith and Vreeland 2006). ${ }^{7}$ We show that IMF programs increase the probability of a transition from autocracy to democracy and reduce the survival probability of democracies.

Vreeland (1999) documents one possible channel through which the political effect of international financial institutions may operate: the "scape goat effect" whereby unpopular policies can be blamed on the conditionality imposed by the international financial

\footnotetext{
${ }^{4}$ The paper is also related to a literature on foreign influence on domestic policy choices (Antrás and Padró i Miquel 2011; Aidt and Hwang 2008, 2014). While this literature takes the political regime as given, we are interested in foreign influences on the regime choice itself.

${ }^{5}$ Berger et al. (2013) provide evidence of US and Soviet interventions abroad. They estimate the impact of this as a decline in democracy across the world of about 33 percent. Berger et al. (2013) show that CIA operations abroad help US exporters. Dube et al. (2011) show how (secret) CIA operations are reflected in the share value of US companies operating in the relevant countries.

${ }^{6}$ The influence of the IMF and the World Bank on economic outcomes has also attracted attention but is less relevant for the point we want to stress here. Vreeland (2003), for example, finds that IMF agreements reduce economic growth and increase inequality. Barro and Lee (2005) also find a negative effect on economic growth, but add that IMF loans increase trade openness. See also Stone (2002).

${ }^{7}$ Related to this, Killick (1995) and Dreher (2004) document that the re-election probability of democratically elected leaders is affected by the presence or absence of an IMF program.
} 
institutions (e.g., the IMF). Another channel, documented by Dreher and Vaubel (2004), is that the monies obtained from international financial institutions are sometimes abused by governments to secure and maintain power. We add a third channel: the "golden hello effect" whereby expectations of new loan agreements with an international financial institution immediately after a regime transition can induce regime instability. ${ }^{8}$

The rest of the paper is organized as follows. In section 2, we present the model and derive the new testable implications. In section 3, we lay out our estimation strategy and discuss the data material. In section 4 , we present the main results. In section 5 , we discuss robustness checks. In section 6 , we conclude and discuss some policy implications.

\section{The Model}

In this section, we outline and extend the theory of political transitions proposed by Acemoglu and Robinson (2001). We have simplified the theory in several dimensions, including using a parsimonious specification of the economic structure and imposing a restriction on the set of policy instruments. These simplifications facilitate the exposition but are not critical for the point we want to make.

\subsection{Assumptions}

We consider a society with infinite time horizon, $t=0,1, \ldots \infty$. Incomes are discounted by the factor $\beta$. The society is populated by two groups of individuals. For concreteness, we call them the rich and the poor and index them with $k \in\{P, R\}$. The size of the total population is normalized to 1 . We assume that the poor are the majority and denote the fraction of poor as $\lambda_{P}>\frac{1}{2}$. The political state of the society or its political regime $S_{t}^{\text {Pol }}$ can be either democracy $(\mathcal{D})$, autocracy $(\mathcal{A})$ or $\operatorname{socialism}(\mathcal{S})$, i.e., is $S_{t}^{\text {Pol }} \in\{\mathcal{D}, \mathcal{A}, \mathcal{S}\} .{ }^{9}$ Regime transitions happen through coups, revolutions, or democratizations. ${ }^{10}$ The opportunities for coups and revolutions depend on many different political, technological,

\footnotetext{
${ }^{8}$ Related to this, Dreher and Gassebner (2012) show that remaining under an IMF or World Bank program following the resolution of an economic crisis increases the likelihood of a political crisis. We complement this finding by showing that the anticipation of new programs - with or without an underlying economic crisis - is in itself a source of political instability.

${ }^{9}$ We use these names to describe the regimes for concreteness, but it should be stressed that the model is not restricted to the types of regimes suggested by those names. The key features represented by the three regimes are as follows: (i) the minority (the rich in the model) prefer autocracy to democracy, but a transition to socialism is even worse and (ii) the majority (the poor in the model) prefer socialism to democracy if a transition to socialism could be effected costlessly (which it cannot, as we shall see). Accordingly, many other interpretations of the three regimes are possible. For example regime $\mathcal{A}$ could be restricted democracy with a wealth-qualification on the right to vote; regime $\mathcal{D}$ could be liberal democracy with universal suffrage and regime $\mathcal{S}$ could be an anti-rich populist democracy.

${ }^{10}$ The term revolution should be understood to mean an un-orderly and forced transition while the term democratization means an orderly and voluntary transiton away from autocracy.
} 
and economic factors. To capture this, we assume that the costs of coups and revolutions are stochastic and that they depend on the social state $\left(S_{t}^{s} \in\{L, H\}\right)$. When the social state is $L$, conditions for either a coup or a revolution are favorable and the costs are relatively low (see below). When the social state is $H$, a coup or a revolution is prohibitively costly, i.e., the costs are high. The probability that the social state is $L(H)$ is $\psi(1-\psi) \cdot{ }^{11}$

We specify the per-period incomes of the members of the two groups directly as functions of the political states. We denote per capita income by $y_{k}\left(S_{t}^{P o l}\right)$ for $k \in$ $\{R, P\} .{ }^{12}$ Utility is linear in incomes. Under autocracy, the rich control the government and no redistribution takes place. The income of each rich person is $y_{R}(\mathcal{A})$, while that of a poor person is $y_{P}(\mathcal{A})<y_{R}(\mathcal{A})$. Under democracy, the poor hold the majority and may use the state to redistribute income from the rich. As a consequence, $y_{R}(\mathcal{A})>y_{R}(\mathcal{D})>0$ and $y_{P}(\mathcal{A})<y_{P}(\mathcal{D})$. Finally, under socialism wholesale expropriation of the rich takes place and we assume that $y_{R}(\mathcal{S})=0$ and $y_{P}(\mathcal{S})>y_{P}(\mathcal{D})$. If the political state is autocracy, the poor might initiate a revolution to change the political state from autocracy to socialism. ${ }^{13}$ We assume that socialism is an absorbing state. ${ }^{14}$ During a revolution, however, each poor person loses welfare, $\mu_{S_{t}^{s}}$. How much depends on the social state. If $S_{t}^{s}=H$, then $\mu_{H}=\infty$ and the poor never attempt a revolution. If, on the other hand, $S_{t}^{s}=L$, then $\mu_{L}=\mu<\infty$ and they might be willing to pay the price of a revolution. In an attempt to avoid a revolution, the rich may introduce democracy. A transition to democracy may, however, be temporary only: the rich can mount a coup to reinstate autocracy. A coup is costly because of the turmoil it creates. As a consequence, each rich citizen suffers a welfare loss, $\phi_{S_{t}^{s}}$, during a coup. How big this loss is, again, depends on the social state. If $S_{t}^{s}=H$, then $\phi_{H}=\infty$ and the rich never attempt a coup. If, on the

\footnotetext{
${ }^{11}$ Acemoglu and Robinson (2001) link the conditions for social unrest directly to the business cycle and assume that coups and revolutions can only take place during recessions. Burke and Leigh (2010), Brückner and Ciccone (2011) and Aidt and Leon (2016) provide empirical justification for this assumption. Economic shocks are, however, only one factor amongst many which make revolutions and coups possible. We prefer for that reason to assume that the costs of coups and revolutions themselves are stochastic.

${ }^{12}$ These incomes can be derived from more fundamental assumptions about endowments, production technologies and tax instruments as in Acemoglu and Robinson (2001). Doing so complicates the analysis without affecting our main results.

${ }^{13}$ As stressed by Tullock (1971) and Kuran (1989), it is the private returns, not the public goods value of regime change, that matter for an individual's incentive to participate in a revolution (or a coup). We follow Acemoglu and Robinson (2000, p. 1172) and assume that each poor can be excluded from the benefit of a revolution if he does not participate. This eliminates any free rider problem, but there could still be a coordination problem. Ellis and Fender (2011) show how one can integrate this aspect into the model. Doing so is not essential for our purposes.

${ }^{14}$ This is a simplifying assumption that could be relaxed. However, doing so would distract from the main message we want to convey through the model without affecting it substantially.
} 
other hand, $S_{t}^{s}=L$, then $\phi_{L}=\phi<\infty$ and the rich might be willing to pay the price of a coup.

The new feature of the model is the "golden hello" - the welcome gift to a new regime.

Definition (Golden Hello). A golden hello is an exogenous one-off transfer of resources from abroad to the (home) society in the period immediately after a transition to either democracy or to autocracy. ${ }^{15}$

The golden hello represents a resource inflow from abroad that is triggered by a regime transition. It should be understood as extra resources over and above the normal inflow of aid and loans from abroad, which are included in the definitions of $y_{R}$ and $y_{P}$. The leading example of this is a new loan agreement with the IMF or the World Bank, but bilateral development aid can also serve our purpose. We make two specific assumptions about the nature of the golden hello.

Assumption 1: The citizens believe that a regime transition from democracy to autocracy or vice versa triggers a golden hello with probability $p$. The draw takes place immediately after each transition. The size of the golden hello, if granted, is $\sigma_{j} j \in\{\mathcal{A}, \mathcal{D}\}{ }^{16}$

Assumption 1 states that there is uncertainty about whether a golden hello will be granted or not. This uncertainty is not resolved until after a transition has taken place. An implication, then, is that decisions to trigger political transitions are based on the citizens' belief that a golden hello is forthcoming, as captured by the probability $p .{ }^{17}$ This probability could depend on the type of transition. However, since our data is not fine enough to capture such a distinction, we do not model this possibility explicitly, although it would be a trivial matter to build this into the model.

\footnotetext{
${ }^{15}$ Logically, there is a third possibility, namely that a socialistic regime (after a revolution) receives a transfer. Although this might have been important during the Cold War, we do not consider this in the present paper. We believe that the analysis of transitions to and from socialism is an important topic that deserves attention, but it goes beyond the scope of the present paper to provide a proper analysis (see Gilli and Li 2015). What we can say within the current framework is this. As in Acemoglu and Robinson (2001) transitions to socialism do not happen in equilibrium. As a consequence, a golden hello to a newly established socialistic regime will not actually trigger such transitions. What it will do is to make a transition to democracy more likely because it makes the poor more willing to challenge an autocracy and the rich will respond by sharing power with the poor under democracy.

${ }^{16}$ For simplicity, we take the size of the golden hello as given. Empirically, we measure if a golden hello is granted or not and not the size of it. This justifies focusing the theory on that aspect. It is straightforward, however, to introduce uncertainty about size of the golden hello.

${ }^{17}$ The probability $p$ should be understood as a subjective probability. Citizens estimate it from relevant information. This may include information about golden hellos granted to other countries or to the country itself in the past. We assume, for simplicity, that the rich and the poor hold the same subjective beliefs. Ordinary workers may not be knowledgeable about the possibility of a golden hello, but it is reasonable to presume that the vanguard - the leaders of any attempt of revolution - do understand the logic of the golden hello. The same is true for the rich.
} 
Assumption 2: The golden hello is divided across the population according to given sharing rules $s_{j}^{k}$ for $j \in\{\mathcal{A}, \mathcal{D}\}$ and $k \in\{P, R\}$. The expected per capita transfer to a member of group $k$ after a transition to regime $j$ is

$$
\sigma_{j}^{k}=\frac{s_{j}^{k} p \sigma_{j}}{\lambda_{k}} \geq 0
$$

Assumption 2 determines how the benefit of the golden hello is distributed between the rich and the poor. This may depend on many factors including which type of transition triggered the golden hello. For example, one may conjecture that the share of the benefits that the rich get after a transition to autocracy is larger than after a transition to democracy and vice versa. ${ }^{18}$ As we shall see, what matters for our main result is that the poor benefit from a golden hello granted after a transition to democracy and that the rich benefit from a golden hello granted after a transition to autocracy. ${ }^{19}$

The timing of events within each period is as follows:

1. The social state $S_{t}^{s} \in\{L, H\}$ is revealed.

2. If a revolution has happened in the past, then the political regime is socialism and the period ends and incomes are $y_{i}(\mathcal{S})$ for $i \in\{R, P\}$.

3. If $S_{t}^{\text {Pol }}=\mathcal{D}$, the rich may initiate a coup that leads to autocracy. If a transition to autocracy takes place, then the game proceeds to stage 5. If no transition to autocracy takes place, then the game proceeds to stage 4 . If $S_{t}^{P o l}=\mathcal{A}$, the rich may democratize. Whether the rich democratize or not, the game proceeds to stage 4 .

4. The poor can initiate a revolution which leads to socialism. If no revolution takes place, the political regime remains as determined in stage 3 ; if a revolution takes place the political regime is socialism.

5. Incomes are determined by the prevailing political regime and the period ends. If a political transition to either $\mathcal{A}$ or $\mathcal{D}$ happened within the period, the size of the golden hello is realized and the transfer is distributed among the population.

\footnotetext{
${ }^{18}$ In transitions to democracy, the rich could, in principle, be excluded from the benefits by the majority of poor if we interpret the value of the golden hello literally as a monetary transfer that the rulers of a country can split in any way they like. However, new agreements with the international financial organizations do not offer that sort of flexibility and they often help alleviate underlying economic problems and the rich will, at least partly, benefit from that. Likewise, the elite would find it difficult to entirely exclude the poor from all benefits after a transition to autocracy.

${ }^{19}$ We assume that the golden hello is a benefit to the country that gets it and this is reflected in the types of loans and grants we use to measure the golden hello empirically. It is possible that some groups could be worse off as a consequence of the entire package of reforms imposed by international lenders. In such cases, the logic of the golden hello does not apply.
} 
We treat the members of the two groups as two players of a dynamic game. We restrict attention to pure strategy Markov perfect equilibria (MPEs) which we define in Appendix B. We assume that the initial political state is autocracy. We note that the timing of events implies that after a coup the poor cannot within the same period start a revolution.

\subsection{Analysis}

The effect of the golden hello on regime dynamics and stability depends on three considerations: i) whether the poor can credibly threaten to organize a revolution or not; ii) whether the rich can head of a revolution through democratization or not; and iii) whether the rich have an incentive to mount a coup after a transition to democracy or not.

The decision to organize a revolution is made by the poor at stage 4 of the game. If a revolution takes place, the outcome is a transition to socialism for ever and each poor citizen gets $\frac{y_{P}(\mathcal{S})}{1-\beta}-\mu_{S_{t}^{s}}$. It is clear that they have no incentive to organize a revolution in social state $H$ (as $\mu_{H}=\infty$ ). In social state $L$, on the other hand, they might organize a revolution, but it depends on how badly they fare under autocracy. Under (perpetual) autocracy, each poor citizen gets $\frac{y_{P}(\mathcal{A})}{1-\beta}$. Therefore, the poor never organize a revolution in state $(L, \mathcal{A})$ when

$$
\mu \geq \mu^{*} \equiv \frac{y_{P}(\mathcal{S})-y_{P}(\mathcal{A})}{1-\beta} .
$$

Intuitively, when the cost of revolution is low relative to the income difference between socialism and autocracy, the so-called "revolution constraint" binds, , i.e., $\mu<\mu^{*}$. In this case, the rich must act in stage 3 to prevent a transition to socialism in social state $L$. We make the following assumption.

Assumption 3: The revolution constraint binds in social state $L: \mu<\mu^{*}$.

The only way (in our formulation of the model) for the rich to preempt a revolution in social state $L$ is to give the poor the right to vote. ${ }^{20}$ As in Acemoglu and Robinson (2001) two types of democracy can emerge as a consequence of a franchise extension. First, consolidated democracy emerges when the transition is permanent. Second, unconsolidated

\footnotetext{
${ }^{20}$ In reality, the rich also have the option of investing resources in repression, e.g., in a police or defense force. Rosendorff (2001), for example, in his theory of democratization stresses this as one of the main coping strategies other than suffrage reform that an elite can employ to hold on to power. Aguirre (2016) stresses the role on uncertainty about the costs of repression in his theory. Acemoglu and Robinson $(2000,2001)$ emphasize transfers or other policy concession as yet another alternative and point to the commitment value of democracy. For the argument that we want to make here, this is not important. For the sake of simplicity, we thus exclude these possibilities.
} 
democracy emerges when the transition is only temporary because the rich mount a coup at the next opportunity (i.e., the next time the state is $(L, \mathcal{D})$ ), for again to issue voting rights when the situation requires it (i.e., in state $(L, \mathcal{A})$ ). Without the golden hello, it is obvious that the poor prefer consolidated to unconsolidated democracy. However, since they expect to benefit from the golden hello each time there is a regime transition, they could, in principle, prefer unconsolidated to consolidated democracy simply because the former is expected to trigger repeated golden hellos. To rule this out, we make the following assumption:

Assumption 4: The expected value of a golden hello for the poor after a transition to democracy is bounded:

$$
\sigma_{\mathcal{D}}^{P}<\frac{y_{P}(\mathcal{D})-y_{P}(\mathcal{A})-(1-\beta(1-\psi)) \sigma_{\mathcal{A}}^{P}}{\beta \psi}
$$

Democratization may, however, not be sufficient to preempt a revolution in stage 4. Intuitively, the income of the poor is higher under socialism than under democracy $\left(y_{P}(\mathcal{S})>y_{P}(\mathcal{D})\right)$ and they may, therefore, prefer to go ahead with a revolution in social state $L$ unless the cost of a revolution is sufficiently large. Assumption 4 implies that the poor prefer consolidated to unconsolidated democracy. Consequently, if unconsolidated democracy can preempt a revolution, then consolidated democracy can do the same. Thus, it is sufficient to establish a condition under which unconsolidated democracy can preempt a revolution. The condition is $\mu>\underline{\mu}\left(\sigma_{\mathcal{D}}^{P}, \sigma_{\mathcal{A}}^{P}\right),{ }^{21}$ where

$$
\begin{aligned}
\underline{\mu}\left(\sigma_{\mathcal{D}}^{P}, \sigma_{\mathcal{A}}^{P}\right) \equiv & \frac{y_{P}(\mathcal{S})-y_{P}(\mathcal{D})}{1-\beta}+\frac{\beta \psi\left(y_{P}(\mathcal{D})-y_{P}(\mathcal{A})\right)}{(1-\beta(1-2 \psi))(1-\beta)} \\
& -\frac{(1-\beta(1-\psi))^{2} \sigma_{\mathcal{D}}^{P}+\beta \psi(1-\beta(1-\psi)) \sigma_{\mathcal{A}}^{P}}{(1-\beta(1-2 \psi))(1-\beta)} .
\end{aligned}
$$

The condition states, for $\sigma_{\mathcal{D}}^{P}=\sigma_{\mathcal{A}}^{P}=0$, that the cost of revolution must be larger than the discounted income difference for the poor between socialism and democracy plus the probability discounted income difference between democracy and autocracy. If the transition to democracy was permanent, then it would be sufficient that the cost of revolution was less than $\frac{y_{P}(\mathcal{S})-y_{P}(\mathcal{D})}{1-\beta}$. However, if the transition is only temporary, the cost has to be higher to account for the income loss suffered by the poor each time there is a transition back to autocracy. Expectations of golden hellos reduce the critical value because the temporary transition to democracy becomes more valuable when each transition, in expectation, triggers a golden hello. We notice that $\underline{\mu}\left(\sigma_{\mathcal{D}}^{P}, \sigma_{\mathcal{A}}^{P}\right)<\mu^{*}$ for $y_{P}(\mathcal{D})>y_{P}(\mathcal{A})$. We make the following assumption:

\footnotetext{
${ }^{21}$ We derive this condition in Appendix B.
} 
Assumption 5: Unconsolidated democracy can prevent a revolution: $\mu>\underline{\mu}\left(\sigma_{\mathcal{D}}^{P}, \sigma_{\mathcal{A}}^{P}\right)$.

Assumption 5 implies that the poor prefer unconsolidated democracy, where the rich democratize each time the state is $(L, \mathcal{A})$ and mount a coup the next time the state is $(L, \mathcal{D})$, to a revolution and a permanent transition to socialism. Combined with Assumption 4, consolidated democracy can also prevent a revolution. We make one additional parameter assumption:

Assumption 6: The expected value of a golden hello for the rich after a transition to democracy is bounded: ${ }^{22}$

$$
\sigma_{\mathcal{D}}^{R}<\min \left\{\frac{y_{R}(\mathcal{A})-y_{R}(\mathcal{D})}{1-\beta}, \frac{y_{R}(\mathcal{A})-y_{R}(\mathcal{D})}{1-(1-\psi) \beta}+\frac{\psi \beta\left(\phi-\sigma_{\mathcal{A}}^{R}\right)}{1-(1-\psi) \beta}\right\}
$$

Assumption 6 rules out that the rich want to democratize without any threat of revolution simply to get the golden hello. While this is an interesting theoretical possibility, its empirical relevance is questionable. ${ }^{23}$

With Assumptions 4 to 6 in place, a transition to democracy will eventually happen because the rich grant voting rights to avoid revolution. Their incentive to do so is present each time the political state is autocracy and the social state is $L$. Whether the democracy consolidates or not depends on the incentives of the rich to mount coups. This incentive is controlled by the so-called "coup constraint". To derive this constraint suppose that the political state is democracy and let $W_{k}\left(S_{t}^{P o l}\right)$ be the continuation value for group $k$ when the political state is $S_{t}^{P o l}$. Clearly, in social state $H$, the rich will not mount a coup because $\phi_{H}=\infty$. In social state $L$, the situation is different. If they do not mount a coup, they get $y_{R}(\mathcal{D})+\beta W_{R}(\mathcal{D})$, and if they do, the coup triggers a golden hello to the new autocracy and they expect to get $y_{R}(\mathcal{A})-\phi+\sigma_{\mathcal{A}}^{R}+\beta W_{R}(\mathcal{A})$. The rich mount a coup if

$$
\phi<y_{R}(\mathcal{A})-y_{R}(\mathcal{D})+\beta\left(W_{R}(\mathcal{A})-W_{R}(\mathcal{D})\right)+\sigma_{\mathcal{A}}^{R}
$$

By assumption, the current political state is democracy. Assumption 3 implies that the rich were forced to democratize the last time the state was $(L, \mathcal{A})$ and that they will have to do so again next time the state is $(L, \mathcal{A})$. This implies that the value of autocracy is

$$
W_{R}(\mathcal{A})=\psi\left(y_{R}(\mathcal{D})+\sigma_{\mathcal{D}}^{R}+\beta W_{R}(\mathcal{D})\right)+(1-\psi)\left(y_{R}(\mathcal{A})+\beta W_{R}(\mathcal{A})\right),
$$

\footnotetext{
${ }^{22}$ The condition is derived in Appendix B.

${ }^{23}$ We refer the interested reader to the working paper version of the paper (Aidt et al. 2012) where we study the scenario in detail. We stress that the golden hello increases regime volatility whether the revolution constraint binds or not, i.e., our empirical test applies to both cases.
} 
where we notice that the transition back to democracy (if the social state is $L$ in the next period) triggers another golden hello with expected value $\sigma_{\mathcal{D}}^{R}$ to the rich this time granted to the new democracy. Combining this with the observation that $W_{R}(\mathcal{D})=$ $y_{R}(\mathcal{D})+\beta W_{R}(\mathcal{D})$ under condition $(6)$, we can write the coup constraint as $\phi<\bar{\phi}\left(\sigma_{\mathcal{A}}^{R}, \sigma_{\mathcal{D}}^{R}\right)$, where

$$
\bar{\phi}\left(\sigma_{\mathcal{A}}^{R}, \sigma_{\mathcal{D}}^{R}\right) \equiv \frac{\left(y_{R}(\mathcal{A})-y_{R}(\mathcal{D})\right)+\psi \beta \sigma_{\mathcal{D}}^{R}+(1-(1-\psi) \beta) \sigma_{\mathcal{A}}^{R}}{(1-(1-\psi) \beta)} .
$$

If this constraint holds, then the coup constraint binds and the rich mount a coup in state $(L, \mathcal{D})$. The cut-off $\bar{\phi}$ has a natural interpretation. A coup is more likely to pay off when the payoff differential between autocracy and democracy, $y_{R}(\mathcal{A})-y_{R}(\mathcal{D})$, is large and when the expected benefit from the golden hellos that repeated transitions between autocracy and democracy could trigger are large.

\subsection{Theoretical results}

Before we state the main result, it is useful to consider the benchmark case in which the golden hello, if it is granted, is unanticipated. Since neither the rich nor the poor expect a golden hello, $\sigma_{j}^{k}=0$ for all $j$ and $k$ and definitions (4) and (8) simplify to

$$
\begin{gathered}
\bar{\phi}(0,0) \equiv \frac{\left(y_{R}(\mathcal{A})-y_{R}(\mathcal{D})\right)}{(1-(1-\psi) \beta)} . \\
\underline{\mu}(0,0) \equiv \frac{y_{P}(\mathcal{S})-y_{P}(\mathcal{D})}{1-\beta}+\frac{\beta \psi\left(y_{P}(\mathcal{D})-y_{P}(\mathcal{A})\right)}{(1-\beta(1-2 \psi))(1-\beta)} .
\end{gathered}
$$

The equilibrium regime dynamics with unanticipated golden hellos is similar to Acemoglu and Robinson (2001). When the cost of revolution is in the range $\left(\underline{\mu}(0,0), \mu^{*}\right)$, the poor are willing to revolt in social state $L$ but will call off the revolution if offered voting rights, temporarily or permanently. In this case, the rich offer voting rights to the poor the first time the social state is $L$. Whether this leads to consolidated democracy or not depends on the cost of a coup. If the cost is high $(\phi>\bar{\phi}(0,0))$, then the democracy consolidates. If the cost is sufficiently low $(\phi<\bar{\phi}(0,0))$, then unconsolidated democracy with frequent regime transitions emerges. The reason, of course, is that the rich are only willing to mount coups when it is not too costly to do so. Along the equilibrium path, golden hellos are occasionally granted, but they do not play any role for the regime dynamics: they are simply incidental, windfall gains.

The situation is fundamentally different when the golden hellos are anticipated by the rich and the poor prior to any actual regime transition. In this case, the golden hello plays a key role for the resulting regime dynamics. To see why, we observe that the 
fundamental thresholds that define the regime boundaries are functions of the expected values of the golden hellos.

Firstly, expectations of golden hellos affect regime dynamics through the revolution constraint. From equation (4), we observe that $\underline{\mu}\left(\sigma_{\mathcal{D}}^{P}, \sigma_{\mathcal{A}}^{P}\right)$ is decreasing in $\sigma_{\mathcal{D}}^{P}$ and $\sigma_{\mathcal{A}}^{P}$ and that $\underline{\mu}\left(\sigma_{\mathcal{D}}^{P}, \sigma_{\mathcal{A}}^{P}\right)<\underline{\mu}(0,0)$ for all $\sigma_{\mathcal{D}}^{P}>0$ or $\sigma_{\mathcal{A}}^{P}>0$. This means that the anticipation of a golden hello, which will partly benefit the poor, increases the range of values of the cost of revolution for which the rich can prevent a revolution by granting temporary voting rights. This makes the initial transition from autocracy to democracy, as well as any subsequent democratic reversals after a coup, more likely. The reason is that the poor value democratic transitions more relative to transitions to socialism when they expect to share the golden hello triggered by the transition now and in the future.

Secondly, expectations of golden hellos also affect regime dynamics through the coup constraint. An increase in the expected value of the golden hello to either a newly established autocracy or to a newly established democracy for the rich increases $\bar{\phi}\left(\sigma_{\mathcal{A}}^{R}, \sigma_{\mathcal{D}}^{R}\right){ }^{24}$ This means that the range of the cost of a coup for which the rich are willing to mount a coup against a democracy goes up and that unconsolidated democracy becomes more likely. Compared to the case where the golden hello in unanticipated, this induces regime instability and the society will over time experience repeated transitions from autocracy to democracy and back again. The following proposition summarizes the regime dynamics with anticipated golden hellos.

Proposition 1 Suppose the initial political state is autocracy, that Assumptions 4 and 6 hold and that

$$
\mu \in\left(\underline{\mu}\left(\sigma_{\mathcal{D}}^{P}, \sigma_{\mathcal{A}}^{P}\right), \mu^{*}\right) \text { with } \underline{\mu}\left(\sigma_{\mathcal{D}}^{P}, \sigma_{\mathcal{A}}^{P}\right)<\underline{\mu}(0,0) .
$$

Then, for all $\phi \neq \bar{\phi}\left(\sigma_{\mathcal{A}}^{R}, \sigma_{\mathcal{D}}^{R}\right)>\bar{\phi}(0,0)$ there exists a unique pure strategy MPE such that

1. If $\phi>\bar{\phi}\left(\sigma_{\mathcal{A}}^{R}, \sigma_{\mathcal{D}}^{R}\right)$, then the economy becomes a consolidated democracy. The rich democratize the first time the social state is $L$ and never attempt a coup after that.

2. If $\phi<\bar{\phi}\left(\sigma_{\mathcal{A}}^{R}, \sigma_{\mathcal{D}}^{R}\right)$ then the economy becomes an unconsolidated democracy. The rich democratize each time the state is $(L, \mathcal{A})$ and mount a coup each time the state is $(L, \mathcal{D})$.

Proof. See Appendix B.

Proposition 1 highlights two important points. Firstly, the anticipation of golden hellos makes democratization more likely, but at the same time, such expectations decrease ${ }^{24} \bar{\phi}\left(\sigma_{\mathcal{A}}^{R}, \sigma_{\mathcal{D}}^{R}\right)>\bar{\phi}(0,0)$ for $\sigma_{\mathcal{A}}^{R}>0$ or $\sigma_{\mathcal{D}}^{R}>0$. 
the likelihood that democracy will consolidate. Secondly, the proposition highlights that the distributional impact of the golden hello matters: democracy as a vehicle for preempting revolution becomes more effective if the poor expect to benefit from the golden hello; coups against unconsolidated democracies become more likely if the rich expect to benefit from the golden hello. We can paraphrase this as saying that the anticipation of golden hellos increases the benefit to the class that would already benefit from a transition to either democracy (the poor) or back to autocracy (the rich).

To map the theory to our empirical specification, it is instructive to imagine a large number of societies indexed by different costs of revolution $(\mu)$ and costs of coups $(\phi)$ drawn from (independent) distributions $F_{\mu}$ and $G_{\phi}$, respectively. We can then write the conditional probability that an autocracy transits to democracy as

$$
\operatorname{Pr}(\mathcal{D} \mid \mathcal{A})=\psi\left(1-F_{\mu}\left(\underline{\mu}\left(\sigma_{\mathcal{D}}^{P}, \sigma_{\mathcal{A}}^{P}\right)\right)\right)
$$

and the conditional probability that a democracy transits to autocracy as

$$
\operatorname{Pr}(\mathcal{A} \mid \mathcal{D})=\psi G_{\phi}\left(\bar{\phi}\left(\sigma_{\mathcal{A}}^{R}, \sigma_{\mathcal{D}}^{R}\right)\right)
$$

By Assumptions 1 and 2, $\sigma_{j}^{k}$ is increasing in the subjective probability $p$ that a golden hello is triggered by a regime transition. Accordingly, the conditional regime transition probabilities are increasing in $p$. The extended version of Acemoglu and Robinson's theory of political transitions, therefore, has a clear-cut testable implication:

Prediction 1 An increase in the subjective probability of a golden hello, either to a newly established democracy or to a newly established autocracy, increases the conditional probability of a transition from democracy to autocracy through a coup and the probability of a transition from autocracy to democracy through a pre-emptive democratization.

\section{Empirical Specification}

To test Prediction 1, we need to measure the golden hellos empirically. We define a golden hello as a new loan program with the International Monetary Fund (IMF) or the World Bank (WB) within a two-year window after a regime transition and we record the number of such new programs started within that time window. Specifically, we consider the following loan programs: (a) a new IMF Structural Adjustment and Growth Facility; (b) a new IMF Poverty Reduction and Growth Facility; or (c) a new structural 
adjustment loan from the World Bank. ${ }^{25}$ We have singled out these particular programs because they involve concessional loans and, as such, represent a substantial benefit to the recipient and because they, unlike inflow of development aid more generally, are discrete events that we can observe and code objectively.

Recording the golden hellos is not sufficient for our test. We need to quantify the expectation held at time $t$ by the decision makers in country $i$ that a golden hello would be triggered if a political transition were to take place. We denote the information set upon which they base these expectations by $H_{i t-1}$. Their estimate of the likelihood that a regime transition triggers a golden hello given the information contained in $H_{i t-1}$ is written as $p_{i t}^{e}=E\left(p \mid H_{i t-1}\right)$. We suppose that the political decision makers form adaptive expectations. ${ }^{26}$ They, therefore, base their estimate of the likelihood that a regime transition triggers a golden hello on golden hellos granted to countries in their "neighborhood" in the past. Formally, we define a neighborhood $N$ and calculate $H_{i t-1}$ for each year as the sum of all past golden hellos in that neighborhood:

$$
H_{i t-1}=\sum_{j=1}^{N} \sum_{\tau=\tau^{S}}^{t-1} x_{j, t-1-\tau},
$$

where $x_{j, t-1-\tau}$ is 0 if country $j \in N$ in year $\tau \leq t-1$ did not get any golden hellos; otherwise $x_{j, t-1-\tau}$ counts the number of golden hellos received. $\tau^{S}$ indicates the year (1970) in which our sample starts.

We specify $H_{t-1}$ in different ways. In the first specification, we restrict the neighborhood to the country itself. In doing so, we effectively ask if a country that in the past got one or more golden hellos is more likely to experience a political transition than a country that did not. One problem with this specification is that it is likely that golden hellos granted to a given country in the past are correlated with unobserved factors that affect the likelihood of political transitions in that country in the present. If so, this will bias the inference. To reduce the risk of this, we exclude the most recent golden hello granted to a country in the construction.

Another and more convincing way to overcome this problem is to exclude a country's own history of golden hellos and emphasize that political decision makers in one coun-

\footnotetext{
${ }^{25}$ The source for IMF loan facilities is Dreher (2006). Data on World Bank loans are obtained directly from the webpage of the World Bank (https://finances.worldbank.org/). While a country can only be under one IMF program at a time, more than one World Bank structural adjustment loan can start in a given year.

${ }^{26}$ In the working paper version of the paper (Aidt et al. 2012), we also consider the case with rational expectations. We approximate the rational expectation by the contemporaneous value and the two first leads of an indicator variable that takes the value 1 if a golden hello was, in fact, received. Results from Logit and linear probability IV estimations confirm the findings we obtain under the assumption of adoptive expectations.
} 
try may learn from observing other countries getting golden hellos. It is reasonable to presume that golden hellos received by other countries in the past are unrelated to unobserved political and economic factors triggering regime transitions within a particular country in the present. This suggests that this measure delivers the exogenous variation we need for our test. The downside is that it will only be informative if the political decision makers within a given country, in fact, base their expectations on what has happened in other countries in the past.

In the second specification of $H_{t-1}$, we, therefore, exclude a country's own history and focus on the history of golden hellos within one of two neighborhoods: the whole world or the region in which a country is located. ${ }^{27}$ We refer to these two measures of the history of golden hellows as the World history of golden hellos and the Regional history of golden hellos, respectively. With these two measures, we effectively ask if a country that is located in a neighborhood in which, based on past experience, it is common that the neighbors receive golden hellos are more likely to undergo a political transition than a country located in a neighborhood in which golden hellos are less common. These formulations, however, assume that all golden hellos in the past carry the same weight. It is possible that the more distant past carry less weight. We take that into account in some specifications and replace the variable Regional history of golden hellos with the variable Regional golden hellos, recent which only counts golden hellos in the region of a country in the previous year.

As we are using a number of proxies to capture the expectations of actual "golden hellos", we need to confirm that these variables do actually predict a future "golden hello". We show in Appendix A that this is actually the case. In Tables A1 and A2, we report the results of estimating logit models for the incidence of Democratic and Autocratic golden hellos, respectively, as a function of each of the proxies used in the main analysis. Reassuringly, it is clear that both the own history and the international occurrence of golden hellos are positively associated with the emergence of a golden hello in a specific country in a given year.

We also need to define what we mean by regime transitions from autocracy to democracy or vice versa. Here, our starting point is the dichotomous regime indicator developed by Acemoglu et al. (2014). The advantage of this indicator over other alternatives is that it combines information from a number of existing indicators to produce a consistent

\footnotetext{
${ }^{27}$ We use the World Bank's definition of world regions and consider the following five regions as separate neighborhoods: Europe, the Americas, Asia, Africa and the Middle East.
} 
classification of countries into democracies and autocracies. ${ }^{28}$ This reduces the risk of misclassification.

Before turning to the econometric analysis and results, it is useful to look at the raw data. This allows us to understand the importance of the golden hello and its geographical and temporal spread. Table 1 lists the golden hellos recorded in our sample of 123 developing countries between 1970 and 2002. It includes 24 instances in which the IMF gave a golden hello to a newly established democracy and 8 instances in which a newly established autocracy received one. The corresponding numbers for the World Bank are 37 "democratic" and 16 "autocratic" golden hellos. These numbers, of course, have to be compared to the total number of political regime transitions. In the sample, there is a total of 106 transitions from autocracy to democracy and 55 transitions from democracy to autocracy. Thus, regime transitions are themselves infrequent events, but they are often accompanied by a golden hello.

This suggests that the golden hello could play a role, but regime transitions are obviously affected by many other factors. The theoretical literature points to a large number of economic and political factors that could potentially cause regime transitions. Przeworski et al. (2000) stress that it is important to distinguish transitions from autocracy to democracy from transitions from democracy to autocracy because the two phenomena could have different determinants. Consequently, we want to study the two types of transitions separately in order to allow the determinants to depend on the direction of the transition.

As in Przeworski et al. (2000), we model the probability of observing democracy in country $i$ in year $t$ as a first order Markov process. Let $D_{i t}$ be a dummy variable coded 1 if country $i$ is a democracy at time $t$, and 0 otherwise. Then, the probability that the country is in state $D_{i t}$ at time $t$ conditional on being in state $D_{i t-1}$ at time $t-1$ can be written as

$$
\operatorname{Pr}\left(D_{i t} \mid D_{i t-1}\right)=\left(1-D_{i t-1}\right) \cdot \operatorname{Pr}\left(D_{i t} \mid D_{i t-1}=0\right)+D_{i t-1} \cdot \operatorname{Pr}\left(D_{i t} \mid D_{i t-1}=1\right)
$$

Since the corresponding likelihood function is additively separable, this Markov process can be estimated as two logistic functions with transition probabilities defined as follows

$$
\begin{aligned}
& \operatorname{Pr}\left(D_{i t} \mid D_{i t-1}=0\right)=\Lambda\left(\alpha^{A D} p_{i t}^{e}, X_{i t-1}^{A D} \beta^{A D}\right) \\
& \operatorname{Pr}\left(D_{i t} \mid D_{i t-1}=1\right)=\Lambda\left(\alpha^{D D} p_{i t}^{e}, X_{i t-1}^{D D} \beta^{D D}\right),
\end{aligned}
$$

\footnotetext{
${ }^{28}$ The regime indicator consolidates information from the Freedom House index, the Polity IV index, and the regime indicators constructed by Przeworski et al. (2000), by Boix et al. (2013) and by Papaioannou and Siourounis (2008). Gründler and Krieger (2016) propose an alternative construction which uses machine learning to aggregate the available democracy indicators.
} 
Table 1: Overview of the Golden Hellos

\begin{tabular}{|c|c|c|c|c|}
\hline \multirow{2}{*}{ Country } & \multicolumn{2}{|c|}{ IMF } & \multicolumn{2}{|c|}{ World Bank } \\
\hline & Democratic & Autocratic & Democratic & Autocratic \\
\hline Albania & 1992,1997 & 1996 & 1992,1997 & 1996 \\
\hline Armenia & & 1996 & & 1996 \\
\hline Azerbaijan & & & & 1993 \\
\hline Bangladesh & & & 1991 & 1974 \\
\hline Belarus & & & 1991 & \\
\hline Benin & 1991 & & 1991 & \\
\hline Brazil & & & 1985 & \\
\hline Bulgaria & & & 1991 & \\
\hline Burundi & 2003 & & & \\
\hline Cambodia & 1993 & & 1993 & 1995 \\
\hline Central African Republic & & & & 2003 \\
\hline Comoros & 1990 & & 1990 & \\
\hline Congo Republic & & & 1992 & \\
\hline Cote d'Ivoire & 2000 & 2002 & & 2002 \\
\hline Croatia & & & 2000 & \\
\hline Djibouti & 1999 & & 1999 & \\
\hline Ethiopia & 1995 & & & \\
\hline Georgia & 1995 & & 1995 & \\
\hline Ghana & & & 1996 & 1981 \\
\hline Guinea-Bissau & 1994,1999 & 1998 & 1999 & 1998 \\
\hline Guyana & 1992 & & 1992 & \\
\hline Haiti & 1994 & & & \\
\hline Indonesia & & & 1999 & \\
\hline Kenya & 2002 & & 2002 & \\
\hline Lebanon & & & & 1975 \\
\hline Lesotho & 1999 & & & \\
\hline Malawi & 1994 & & & \\
\hline Mali & 1992 & & 1992 & \\
\hline Mexico & & & 1997 & \\
\hline Moldova & & & 1994 & \\
\hline Mongolia & 1993 & & & \\
\hline Mozambique & 1994 & & 1994 & \\
\hline Nicaragua & & & 1990 & \\
\hline Niger & 1999 & 1996 & 1999 & 1996 \\
\hline Nigeria & & & & 1984 \\
\hline Nepal & 1991 & 2002 & & \\
\hline Pakistan & 1998 & 1999 & 1972,1998 & 1999 \\
\hline Peru & & & 1993 & 1992 \\
\hline Philippines & & & 1987 & \\
\hline Poland & & & 1990 & \\
\hline Romania & & & 1990 & \\
\hline Sierra Leone & 2001 & & 1996,2001 & \\
\hline Slovak Republic & & & 1993 & \\
\hline Slovenia & & & 1992 & \\
\hline Turkey & & & 1983 & 1980 \\
\hline Uganda & & 1985 & 1980 & 1985 \\
\hline Uruguay & & & 1985 & \\
\hline Total & 24 & 8 & 37 & 16 \\
\hline
\end{tabular}

Notes: This table reports all instances of golden hellos defined as new IMF or World Bank programs within two years of democratic regime changes (from autocracy) or autocratic changes (from democracy). Regime changes are coded from Acemoglu et al. (2014). Countries in our sample not listed in the table did not get a golden hello. 
where $\Lambda$ is the cumulative distribution function of the logistic distribution, superscript $A D$ denotes transitions from autocracy to democracy, and superscript $D D$ denotes the survival of democracy, i.e., the flip side of transitions from democracy to autocracy. ${ }^{29}$ Based on our theoretical predictions on the effect of a (expected) golden hello $\left(p_{i t}^{e}\right)$, we anticipate $\alpha^{A D}>0$ and $\alpha^{D D}<0$.

To select the set of control variables in the two vectors $X_{i t-1}^{A D}$ and $X_{i t-1}^{D D}$, we build on Gassebner et al. (2013). They undertake an extreme bounds analysis (EBA) to establish which of the 59 potential determinants of regime transitions proposed in the vast empirical literature on the subject are robust in the sense of Sala-i Martin (1997). ${ }^{30}$ The extreme bounds analysis confirms that the determinants of the two types of regime transitions are different. For transitions to democracy, the growth rate of purchasing power parity adjusted GDP per capita (Growth of GDP p.c. PPP), previous regime transitions (Previous transitions), the share of fuel exports in merchandise exports (Share of fuel exports), a dummy variable for OECD membership (OECD), and the share of Muslims in the population (Muslim) are robust. For democratic survival, the robust variables are the level of GDP per capita (GDP p.c. PPP), previous regime transitions, a dummy variable indicating whether the head of state is a (former) military officer (Military leader), and the level of democracy in neighboring countries (Neighboring democracies). ${ }^{31}$ We use these variables (lagged by one year) as the baseline and add the golden hello variables to this specification. Of course, one could choose other control variables, but our approach, based on the extreme bounds methodology, has the advantage of being objective, datadriven, and systematic. Table 2 shows descriptive statistics of the variables used in the econometric analysis.

As a preliminary exploration, we provide a graphical representation of the impact of actual golden hellos. We treat a golden hello as an "event" and estimate the probability of a political regime transition two years before and two years after a golden hello. As displayed in Figure 1, the probability of a regime transition is higher after a golden hello, both under a Democracy and Autocracy, and, as reported, this difference is statistically significant according to a test on the equality of means.

\footnotetext{
${ }^{29}$ It is common in the literature to model the probability of democratic survival instead of the probability of transition from democracy to autocracy. We follow this convention but note it is not inconsequential.

${ }^{30}$ Extreme bounds analysis involves a systematic evaluation of all possible (regression) models with regime type as the dependent variable and a fixed number of potential determinants (typically 3 ) from the target list of the explanatory variables. The criterion for robustness suggested by Sala-i Martin (1997) is that 90 percent of the cumulated density associated with the estimated coefficients on the variable of interest (e.g., GDP per capita) across all the models considered should be on one side of zero.

${ }^{31}$ For the sources and details on how these variables are constructed, see Gassebner et al. (2013).
} 
Table 2: Descriptive statistics

\begin{tabular}{lccc} 
Variable & Observations & Mean & Str. Dev. \\
\hline \hline Democracy (outcome variable) & 5,773 & 0.41 & 0.49 \\
\hline Democratic World Bank Golden Hello & 5,773 & 0.01 & 0.09 \\
Democratic IMF Golden Hello & 5,773 & 0.00 & 0.05 \\
Autocratic World Bank Golden Hello & 5,773 & 0.00 & 0.05 \\
Autocratic IMF Golden Hello & 5,773 & 0.00 & 0.02 \\
\hline Regional Democratic Golden Hellos, recent & 5,773 & 0.47 & 0.94 \\
Regional Democratic History of Golden Hellos & 5,773 & 5.93 & 7.85 \\
Regional Autocratic Golden Hellos, recent & 5,773 & 0.11 & 0.38 \\
Regional Autocratic History of Golden Hellos & 5,773 & 5.11 & 6.50 \\
Military Leader & 4,276 & 0.24 & 0.43 \\
Neighboring democracies & 4,781 & 0.36 & 0.38 \\
Previous transitions & 5,250 & 0.37 & 0.75 \\
OECD Countries & 5,773 & 0.14 & 0.35 \\
Muslim Countries & 4,269 & 0.21 & 0.35 \\
Share of fuel exports & 3,249 & 17.71 & 31.01 \\
Growth of GDP p.c. PPP & 4,667 & 3.42 & 6.54 \\
\hline Number of Countries: 123 & & & \\
Years: 1970-2002 & & & \\
\hline \hline
\end{tabular}

Figure 1: Probability of Regime Transition Before and After a Golden Hello

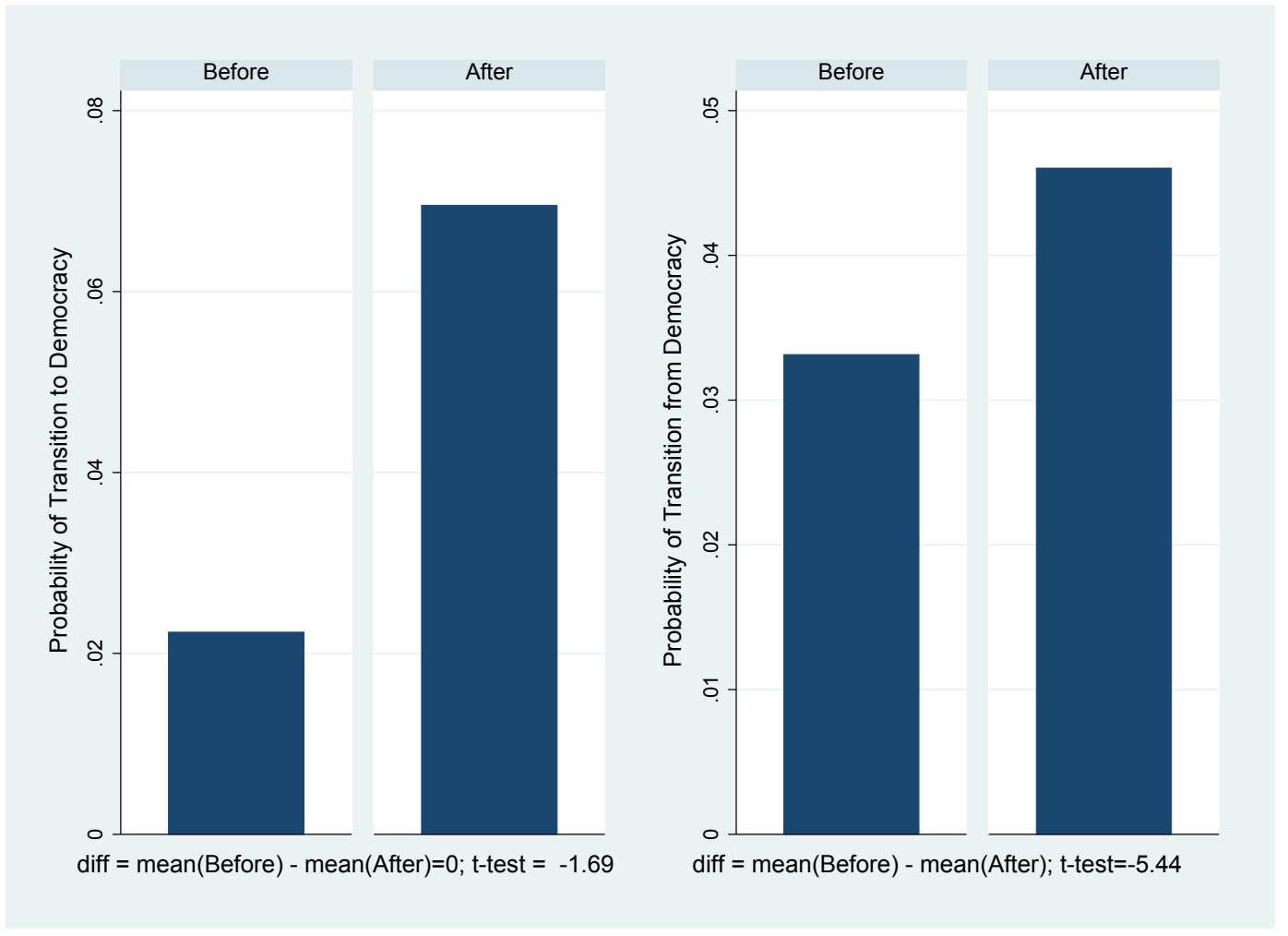


Although suggestive, this result is far from conclusive since actual golden hellos are likely to capture (dynamic and invariant) country specific characteristics and, also, they implicitly require perfect anticipation to have an effect. We turn now to the econometric analysis where we use the different sources of expectations on golden hellos discussed above.

\section{Empirical results}

Tables 3 and 4 present the main results. Table 3 reports the estimated probability of a transition from autocracy to democracy. In specification (1), we proxy the expected golden hello with each country's own history of golden hellos. We see that having received golden hellos in the past increases the odds of a democratic transition by 1.6 percent (= $\exp (0.016))$. This is fairly large, given that the unconditional probability of a transition to democracy is only two percent. Since we exclude the most recent golden hello from the history, the last golden hello recorded is, by construction, at least three years in the past. This mitigates potential endogeneity issues due to reverse causation.

In specifications (2) to (4), we proxy the expected golden hello with the history of golden hellos bestowed on other countries in the region within which a country is located. This further reduces the risk of a bias due to endogeneity. From specification (2), we see that the world history of golden hellos is positively associated with democratic transitions. A one-unit increase in the index of world golden hellos increases the odds of a democratic transition by one percent but the effect is only significant at the 10 percent level. In specifications (3) and (4), we restrict the information set to the region in which a country is located (Europe, the Americas, Asia, Africa, or the Middle East). We see that the regional golden hellos are positively associated with democratic transitions and statistically significant at the one percent level however measured. The magnitude is larger than for the history of own golden hellos. A one-unit increase in the index of the history of regional golden hellos increases the odds of a democratic transition by 3.8 percent (specification (4)). For regional golden hellos in the recent past (specification (3)), the effect is more than 10 times larger.

With regard to the control variables, the results are broadly in line with Przeworski et al. (2000) and Gassebner et al. (2013). We find that GDP per capita does not facilitate democratic transitions. However, previous regime transitions do. Moreover, becoming a member of the OECD also stimulates a democratic transition. ${ }^{32}$ Muslim countries

\footnotetext{
${ }^{32}$ This finding may seem trivial or tautological. It is not, however. Greece, Portugal, Spain, Turkey, and Mexico entered the OECD as autocracies for subsequently to became democracies.
} 
are less likely to become democracies. ${ }^{33}$ As Gassebner et al. (2013) show, this effect is driven by the oil rich Arab countries. This is also the likely reason that the coefficient on fuel exports is statistical insignificance: the two variables are highly collinear. The final control variable, growth rate of GDP per capita, is statistically insignificant, except in two specifications.

Table 3: Transitions to democracy, 1970-2002, Golden Hellos

\begin{tabular}{lcccc}
\hline & $(1)$ & $(2)$ & $(3)$ & $(4)$ \\
\hline \hline log GDP p.c. PPP, t-1 & -0.002 & 0.008 & 0.076 & 0.064 \\
& $(0.215)$ & $(0.215)$ & $(0.108)$ & $(0.125)$ \\
Previous transitions, t-1 & $0.539^{* * *}$ & $0.530^{* * *}$ & $0.487^{* * *}$ & $0.528^{* * *}$ \\
& $(0.149)$ & $(0.150)$ & $(0.134)$ & $(0.140)$ \\
OECD & $2.679^{* * *}$ & $2.660^{* * *}$ & $2.595^{* * *}$ & $2.704^{* * *}$ \\
& $(0.496)$ & $(0.489)$ & $(0.327)$ & $(0.423)$ \\
Muslim & $-1.953^{* * *}$ & $-1.933^{* * *}$ & $-1.697^{* *}$ & $-1.763^{* *}$ \\
& $(0.540)$ & $(0.536)$ & $(0.784)$ & $(0.712)$ \\
Share of fuel exports, t-1 & -0.009 & -0.009 & -0.009 & -0.009 \\
& $(0.011)$ & $(0.011)$ & $(0.010)$ & $(0.009)$ \\
Growth of GDP p.c. PPP, t-1 & -0.026 & -0.025 & $-0.023^{* * *}$ & $-0.027^{* * *}$ \\
& $(0.034)$ & $(0.033)$ & $(0.006)$ & $(0.005)$ \\
Own history of Golden Hellos & $0.016^{* *}$ & & & \\
World History of Golden Hellos & $(0.008)$ & & & \\
Regional Golden Hellos, recent & & $0.011^{*}$ & & \\
Regional History of Golden Hellos & \multicolumn{5}{c}{$0.129^{* * *}$} & \\
Constant & & & & \\
& $-3.247^{* *}$ & $-3.264^{* *}$ & $-3.598^{* * *}$ & $-3.693^{* * *}$ \\
\hline Observations & $(1.527)$ & $(1.524)$ & $(0.998)$ & $(1.157)$ \\
\hline \hline
\end{tabular}

Notes: The table reports logit regressions conditional on being autocratic in $t-1$. The regime type classification is based on Acemoglu et al. (2014). A golden hello is a new loan program with the International Monetary Fund (IMF) or the World Bank (WB) within a two-year window after a regime transition. Standard errors clustered at the country level (columns 1 and 2) and at the region level (columns 3 and 4) are reported in parentheses below the coefficient. ${ }^{*} / * /{ }^{* * *}$ indicate significance at the $10 / 5 / 1 \%$-level.

Table 4 reports the estimated probability of democratic survival, the flip side of a transition from democracy to autocracy. Unfortunately, we cannot construct the golden

\footnotetext{
${ }^{33}$ We note that our sample period does not cover the Arab Spring.
} 
hello variable based on a country's own history because no country in our sample experienced two transitions from democracy to autocracy. Unlike the case with transitions from autocracy to democracy, the world history of golden hellos does not play a role for democratic survival. Importantly, however, the regional history does. Both the full history of regional golden hellos in the past and the history of recent golden hello in the region exhibit a negative and significant effect on democratic survival. In other words, expectations of a golden hello contributes to destabilizing democracies. With regard to the control variables, we confirm that rich democracies are more likely to remain democracies and that previous regime transitions decrease the probability of democratic survival. We also find the expected effect of political leaders with military background and the spillover effect of being surrounded by democracies in two of the three specifications.

Table 4: Democratic survival, 1970-2002, Golden Hellos

\begin{tabular}{lccc}
\hline & $(1)$ & $(2)$ & $(3)$ \\
\hline \hline log GDP p.c. PPP, t-1 & $1.345^{* * *}$ & $1.298^{* * *}$ & $1.329^{* * *}$ \\
Military leader, t-1 & $(0.230)$ & $(0.153)$ & $(0.168)$ \\
& -0.732 & $-0.757^{* * *}$ & $-0.678^{* * *}$ \\
Neighboring democracies & $(0.488)$ & $(0.192)$ & $(0.166)$ \\
& 0.825 & $0.759^{* * *}$ & $0.921^{*}$ \\
Previous transitions, t-1 & $(0.922)$ & $(0.445)$ & $(0.546)$ \\
& $-0.481^{* *}$ & $-0.438^{* *}$ & $-0.545^{* * *}$ \\
World History of Golden Hellos & $(0.233)$ & $(0.226)$ & $(0.207)$ \\
& -0.030 & & \\
Regional Golden Hellos, recent & $(0.041)$ & & $-0.639^{* * *}$ \\
& & $(0.213)$ & \\
Regional History of Golden Hellos & \multicolumn{3}{c}{$-0.062^{*}$} \\
Constant & $-6.192^{* * *}$ & $-6.018^{* * *}$ & $-6.024^{* * *}$ \\
& $(1.559)$ & $(1.085)$ & $(0.909)$ \\
\hline Observations & 1,002 & 1,002 & 1,002 \\
\hline \hline
\end{tabular}

Notes: The table reports logit regressions conditional on being democratic in $t-1$. The regime type classification is based on Acemoglu et al. (2014). A golden hello is a new loan program with the International Monetary Fund (IMF) or the World Bank (WB) within a two-year window after a regime transition. Standard errors clustered at the country level (column 1) and at the region level (columns 2 and 3) are reported in parentheses below the coefficient. ${ }^{*} / * / * *$ indicate significance at the $10 / 5 / 1 \%$-level. 


\section{Robustness tests}

In this section, we discuss a number of robustness checks and permutations of the baseline specifications reported in the previous section. For brevity, we provide short overviews of the results. The detailed results are reported in the Supplementary Appendix.

First, so far we do not distinguish golden hellos originating from the World Bank from those originating from the IMF. However, they might have different effects. For example, Dreher and Gassebner (2012) show that World Bank projects started in the absence of an economic crisis tend to cause a political crisis; the same is not unambiguously true for new IMF programs. To investigate potential asymmetries in the impact on regime transitions of golden hellos from the two international organizations, we have redefined the golden hello variables such that they count the number of golden hellos originating from each of the two separately and re-estimated the logit models. We do not find any evidence of an asymmetry: Golden hellos from either organization increase the odds of a democratic transition and reduces the odds of democracy survival (see Tables A1 to A4 in the Supplementary Appendix).

Second, we reproduce the results reported in Table 3 and 4 with the regime indicator developed by Przeworski et al. (2000). They define a democracy as a political system in which key government offices are filled through contested elections. The term "key government office" refers to the executive and the legislature while the term "contested elections" refers to situations in which more than one party has a chance of winning office. Thus, elections must be associated with some ex ante uncertainty, and be subject to $e x$ post irreversibility, or put succinctly, "democracy is a system in which incumbents lose elections and leave office when the rules so dictate" (Przeworski et al. 2000, p. 54). This coding identifies 16 instances in which the IMF gave a golden hello to a newly established democracy and 4 instances in which a newly established autocracy received one. The corresponding numbers for the World Bank are 49 "democratic" and 13 "autocratic" golden hellos (see Table A5 in the Supplementary Appendix for a complete list). Despite these differences, we obtain results which are qualitatively similar to those reported in Table 3 and 4 with this alternative coding (see Tables A6 and A7 in the Supplementary Appendix). Thus, it does not appear that the results are particularly sensitive to the choice of democracy indicator.

Third, to construct the regional golden hello variables, we simply count the number of golden hellos granted in the relevant region. This may conflate the effect of golden hellos with the effect of being in a region where many political transitions have taken place in the past. To evaluate if this an issue, we "normalize" the two regional golden hello variables with the total number of transitions in the region. For Regional Golden 
Hellos, recent, we normalize with the number of transitions of the same type (either to democracy or to autocracy) in the previous year in the region. For Regional History of Golden Hellos, we normalize with the number of transitions in the same region in the past. Table A8 in the Supplementary Appendix shows that the results are robust to this.

Forth, by construction the own, regional and world histories of golden hellos increase over time. It is, therefore, possible that they pick up a time trend in regime transitions. In Table A9 in the Supplementary Appendix, we report specifications with a set of decade dummy variables added. The effects of the golden hello variables are weaker, but remain statistically significant.

\section{Conclusion}

This paper contributes to an extensive theoretical and empirical literature on the causes of political transitions. Theoretically, we demonstrate within the framework of the model of political transitions developed by Acemoglu and Robinson (2001) how expectations about (concessional) transfers from international financial institutions to newly established political regimes - golden hellos - cause political instability. Empirically, we find that expectations of getting a golden hello from the IMF or the World Bank increase the probability of a transition to democracy but decrease the probability of democratic survival. This finding is new to the literature on the political economy of international organizations. Equally importantly, we provide a new test of Acemoglu and Robinson's theory of political transitions and interpret our evidence as being consistent with this theory.

We show that the golden hello is a source of political instability. In general, this is an undesirable and unintended side-effect of providing newly established political regimes with additional finance. Importantly, however, an obvious and easy-to-implement policy conclusion follows directly from the analysis: golden hellos should only be granted to newly established democracies. The effect of this would be to encourage transitions to democracy while minimizing subsequent incentives for political reversals. A similar effect can be achieved by making sure that the autocratic elites are excluded from any benefits that a golden hello might bring, but that is harder to enforce than regime-specific conditionality. Fostering democracy, accountability, and the rule of law - good governance - is on the agenda of all the major international financial institutions. Selective use of golden hellos could be a useful tool (but clearly not the only one) in pushing this agenda forward. 


\section{References}

Acemoglu, D., S. Naidu, P. Restrepo, and J. A. Robinson (2014, March). Democracy does cause growth. Working Paper 20004, National Bureau of Economic Research.

Acemoglu, D. and J. A. Robinson (2000). Why did the west extend the franchise? Democracy, inequality, and growth in historical perspective. Quarterly Journal of Economics 115(4), 1167-1199.

Acemoglu, D. and J. A. Robinson (2001). A theory of political transitions. American Economic Review 91(4), 938-963.

Acemoglu, D. and J. A. Robinson (2005). Economic origins of dictatorship and democracy. Cambridge, England: Cambridge University Press.

Aguirre, A. (2016). The risk of civil conflicts as a determinant of political institutions. European Journal of Political Economy 42, 36-59.

Aidt, T. and F. Albornoz (2011). Political regimes and foreign intervention. Journal of Development Economics 94(2), 192-201.

Aidt, T. and R. Franck (2015). Democratization under the threat of revolution: Evidence from the great reform act of 1832. Econometrica 83(2), 505-547.

Aidt, T. and U. Hwang (2008). On the internalization of cross-national externalities through political markets: The case of labour standards. Journal of Institutional and Theoretical Economics 164(3), 509-533.

Aidt, T. and U. Hwang (2014). To ban or not to ban: Foreign lobbying and cross-national externalities. Canadian Journal of Economics 47(1), 272-297.

Aidt, T. and P. Jensen (2014). Workers of the world, unite! Franchise extensions and the threat of revolution in europe, 1820-1938. European Economic Review 72, 52-75.

Aidt, T. and G. Leon (2016). The democratic window of opportunity: Evidence from riots in Sub-Saharan Africa. Journal of Conflict Resolution 60(4), 694-717.

Aidt, T. S., F. Albornoz, and M. Gassebner (2012). The golden hello and political transitions. Working Paper 3957, CESifo, Munich.

Alesina, A. and D. Dollar (2000). Who gives foreign aid to whom and why? Journal of Economic Growth 5(1), 33-63. 
Antrás, P. and G. Padró i Miquel (2011). Foreign influence and welfare. Journal of International Economics 84(2), 135-148.

Barro, R. and J.-W. Lee (2005). IMF programs: Who is chosen and what are the effects? Journal of Monetary Economics 52(7), 1245-1269.

Berger, D., A. Corvalan, W. Easterly, and S. Satyanath (2013). Do superpower interventions have short and long term consequences for democracy? Journal of Comparative Economics 41(1), 22-34.

Berger, D., W. Easterly, N. Nunn, and S. Satyanath (2013). Commercial imperialism? Political influence and trade during the cold war. American Economic Review 103(2), 863-896.

Boix, C. (2003). Democracy and redistribution. Cambridge, England: Cambridge University Press.

Boix, C., M. Miller, and S. Rosato (2013). A complete data set of political regimes, 1800-2007. Comparative Political Studies 46(12), 1523-1554.

Bonfatti, R. (2017). An economic theory of foreign interventions and regime change. Canadian Journal of Economics 50(2), 306-339.

Brückner, M. and A. Ciccone (2011). Rain and the democratic window of opportunity. Econometrica 79(3), 923-947.

Burke, P. J. and A. Leigh (2010). Do output contractions trigger democratic change? American Economic Journal: Macroeconomics 2(4), 124-57.

Congleton, R. (2007). From royal to parliamentary rule without revolution: The economics of constitutional exchange within divided governments. European Journal of Political Economy 23(2), 261-284.

Congleton, R. D. (2011). Perfecting Democracy. Cambridge, England: Cambridge University Press.

Dorsch, M. and P. Maarek (2015). Inefficient predation and political transitions. European Journal of Political Economy 37, 37-48.

Dreher, A. (2004). The influence of IMF programs on the re-election of debtor governments. Economics and Politics 16(1), 53-76.

Dreher, A. (2006). IMF and economic growth: The effects of programs, loans, and compliance with conditionality. World Development 34, 769-788. 
Dreher, A. and M. Gassebner (2012). Do IMF and World Bank programs induce government crises? An empirical analysis. International Organization 66(2), 329-358.

Dreher, A. and R. Vaubel (2004). Do IMF and IBRD cause moral hazard and political business cycles? Evidence from panel data. Open Economies Review 15(1), 5-22.

Dube, A., E. Kaplan, and S. Naidu (2011). Coups, corporations, and classified information. Quarterly Journal of Economics 126(3), 1375-1409.

Ellis, C. and J. Fender (2011). Information cascades and revolutionary regime transitions. Economic Journal 121(553), 763-792.

Gassebner, M., M. Lamla, and J. Vreeland (2013). Extreme bounds of democracy. Journal of Conflict Resolution 57(2), 171-197.

Gilli, M. and Y. Li (2015). Coups, revolutions and efficient policies in autocracies. European Journal of Political Economy 39, 109-124.

Gradstein, M. (2007). Inequality, democracy and the protection of property rights. Economic Journal 117(516), 252-269.

Gründler, K. and T. Krieger (2016). Democracy and growth: Evidence from a machine learning indicator. European Journal of Political Economy 45, Supplement, 85 - 107.

Kalyvitis, S. and I. Vlachaki (2012). When does more aid imply less democracy? An empirical examination. European Journal of Political Economy 28(1), 132-146.

Killick, T. (1995). IMF Programmes in Developing Countries: Design and Impact. London, England: Routledge.

Kuran, T. (1989). Sparks and prairie fires: A theory of unanticipated political revolution. Public Choice 61(1), 41-74.

Lizzeri, A. and N. Persico (2004). Why did the elites extend the suffrage? Democracy and the scope of government, with an application to Britain's "age of reform". Quarterly Journal of Economics 119(2), 707-765.

López-Córdova, J. and C. Meissner (2008). The impact of international trade on democracy: A long-run perspective. World Politics 60(4), 539-575.

Papaioannou, E. and G. Siourounis (2008). Democratisation and growth. Economic Journal 118(532), 1520-1551. 
Przeworski, A. (2009). Conquered or granted? A history of suffrage extensions. British Journal of Political Science 39(2), 291-321.

Przeworski, A., M. Alvarez, J. A. Cheibub, and F. Limongi (2000). Democracy and Development: Political Regimes and Economic Well-being in the World, 1950-1990. Cambridge, UK: Cambridge University Press.

Rosendorff, P. B. (2001). Elections as a conflict processing mechanism. European Journal of Political Economy 13, 1-29.

Sala-i Martin, X. (1997). I just ran two million regressions. American Economic Review $87(2), 178-183$.

Smith, A. and J. R. Vreeland (2006). The survival of political leaders and IMF programs. In G. Ranis, J. R. Vreeland, and S. Kosack (Eds.), Globalization and the Nation State: The Impact of the IMF and the World Bank. New York: Routledge.

Stone, R. (2002). Lending credibility: The International Monetary Fund and the postcommunist transition. Princeton: Princeton University Press.

Tullock, G. (1971). The paradox of revolution. Public Choice 11, 89-99.

Vreeland, J. R. (1999). The IMF: Lender of last resort of scapegoat? New Haven: Yale University Press.

Vreeland, J. R. (2003). The IMF and economic development. Cambridge, England: Cambridge University Press. 


\section{Appendix A: Empirics}

Table A1: Democratic Golden Hello and its Proxies

\begin{tabular}{|c|c|c|c|c|}
\hline & $\begin{array}{c}(1) \\
\text { Democratic } \\
\text { Golden Hello }\end{array}$ & $\begin{array}{c}(2) \\
\text { Democratic } \\
\text { Golden Hello }\end{array}$ & $\begin{array}{c}(3) \\
\text { Democratic } \\
\text { Golden Hello }\end{array}$ & $\begin{array}{c}(4) \\
\text { Democratic } \\
\text { Golden Hello }\end{array}$ \\
\hline $\begin{array}{l}\text { Own history } \\
\text { of Golden Hellos }\end{array}$ & $\begin{array}{l}0.528^{* *} \\
(0.207)\end{array}$ & & & \\
\hline $\begin{array}{l}\text { World History } \\
\text { of Golden Hellos }\end{array}$ & & $\begin{array}{r}0.022^{* * *} \\
(0.0033)\end{array}$ & & \\
\hline $\begin{array}{l}\text { Regional Golden Hellos, } \\
\text { recent }\end{array}$ & & & $\begin{array}{c}0.409^{* * *} \\
(0.054)\end{array}$ & \\
\hline $\begin{array}{l}\text { Regional History } \\
\text { of Golden Hellos }\end{array}$ & & & & $\begin{array}{c}0.048^{* *} \\
(0.021)\end{array}$ \\
\hline Constant & $\begin{array}{c}-2.081^{* * *} \\
(0.121)\end{array}$ & $\begin{array}{c}-2.571^{* * *} \\
(0.148)\end{array}$ & $\begin{array}{c}-2.352^{* * *} \\
(0.310)\end{array}$ & $\begin{array}{c}-2.346^{* * *} \\
(0.435)\end{array}$ \\
\hline Observations & 3,480 & 3,480 & 3,480 & 3,480 \\
\hline
\end{tabular}

Robust standard errors in parentheses clustered at the country level (columns 1 and 2) and at the region level (columns 3 and 4 )

$* * * \mathrm{p}<0.01,{ }^{*} * \mathrm{p}<0.05,{ }^{*} \mathrm{p}<0.1$

Table A2: Autocratic Golden Hello and its Proxies

\begin{tabular}{|c|c|c|c|}
\hline & $\begin{array}{c}(1) \\
\text { Autocratic } \\
\text { Golden Hello }\end{array}$ & $\begin{array}{c}(2) \\
\text { Autocratic } \\
\text { Golden Hello }\end{array}$ & $\begin{array}{c}(3) \\
\text { Autocratic } \\
\text { Golden Hello }\end{array}$ \\
\hline $\begin{array}{l}\text { World History } \\
\text { of Golden Hellos }\end{array}$ & $\begin{array}{c}0.027^{* * *} \\
(0.0071)\end{array}$ & & \\
\hline $\begin{array}{l}\text { Regional Golden Hellos, } \\
\text { recent }\end{array}$ & & $\begin{array}{c}0.525^{* * *} \\
(0.163)\end{array}$ & \\
\hline $\begin{array}{l}\text { Regional History } \\
\text { of Golden Hellos }\end{array}$ & & & $\begin{array}{l}0.055^{* *} \\
(0.004)\end{array}$ \\
\hline Constant & $\begin{array}{c}-1.984^{* * *} \\
(0.216)\end{array}$ & $\begin{array}{c}-1.658^{* * *} \\
(0.0849)\end{array}$ & $\begin{array}{c}-2.020^{* * *} \\
(0.0382)\end{array}$ \\
\hline Observations & 1,751 & 1,751 & 1,751 \\
\hline
\end{tabular}




\section{Appendix B: Theory}

Defining equilibrium A Markov perfect strategy determines for each player the appropriate action as a function of the current state of the world only, i.e., $\left(S^{S}, \mathcal{A}\right)$, $\left(S^{S}, \mathcal{D}\right)$ or $\mathcal{S}$, where $S^{S} \in\{L, H\}$. In state $\left(S^{S}, \mathcal{A}\right)$, the action space of the rich consists of a decision to democratize or not, while in state $\left(S^{S}, \mathcal{D}\right)$, the action space of the elite is to mount a coup or not. Since state $\mathcal{S}$ is absorbing, we need notspecify the strategy of the rich in this state. When the state is $\left(S^{S}, \mathcal{A}\right)$, a strategy of the poor is a function of the state of the world and the rich's decision to democratize or not. When the state is $\left(S^{S}, \mathcal{D}\right)$, the poor's strategy is simply a function of the state. The strategy determines the appropriate action of the poor. In state $\left(S^{S}, \mathcal{A}\right)$, their action space is a decision to mount a revolution or not, while in state $\left(S^{S}, \mathcal{D}\right)$, they are not required to take any actions. A pure strategy Markov perfect equilibrium is then defined as a set of strategies for the rich and the poor that are best responses to each other for all possible states.

Deriving condition (4) The poor benefit from a transition to democracy for two reasons. Firstly, their income is higher than under autocracy (but lower than under socialism). Secondly, they share in the golden hello or hellos if multiple transitions take place. We are seeking a condition that ensures that the poor will "cancel" the revolution if the rich grant them voting rights. In the absence of the golden hello, unconsolidated democracy, understood as a situation in which the rich grant voting rights when the state is $(L, \mathcal{A})$ and mount a coup when the state is $(L, \mathcal{D})$, defines a lower bound on the welfare of the poor under democracy. This is also true for positive values of $\sigma_{\mathcal{D}}^{P}$ and $\sigma_{\mathcal{A}}^{P}$ that satisfy

$$
\sigma_{\mathcal{D}}^{P}<\frac{y_{P}(\mathcal{D})-y_{P}(\mathcal{A})-(1-\beta(1-\psi)) \sigma_{\mathcal{A}}^{P}}{\beta \psi}
$$

Thus, if democratization can prevent a revolution by dominating a transition to socialism for $\sigma_{\mathcal{D}}^{P}$ and $\sigma_{\mathcal{A}}^{P}$ satisfying this condition, so can any other type of democracy including a transition to permanent democracy. Formally, we seek a condition that ensures

$$
\frac{y_{P}(\mathcal{S})}{1-\beta}-\mu \leq y_{P}(\mathcal{D})+\sigma_{\mathcal{D}}^{P}+\beta W_{P}(\mathcal{D})
$$

where

$$
\left.W_{P}(\mathcal{D})=\psi\left(y_{P}(\mathcal{A})+\sigma_{\mathcal{A}}^{P}+\beta W_{P}(\mathcal{A})\right)+(1-\psi)\left(y_{P}(\mathcal{D})+\beta W_{P}(\mathcal{D})\right)\right)
$$

and

$$
W_{P}(\mathcal{A})=\psi\left(y_{P}(\mathcal{D})+\sigma_{\mathcal{D}}^{P}+\beta W_{P}(\mathcal{D})\right)+(1-\psi)\left(y_{P}(\mathcal{A})+\beta W_{P}(\mathcal{A})\right) .
$$

This yields two equations in two unknown, which we can solve to get 


$$
\begin{aligned}
W_{P}(\mathcal{D}) & =\frac{\psi y_{P}(\mathcal{A})+(1-\beta(1-2 \psi)-\psi) y_{P}(\mathcal{D})+\beta \psi^{2} \sigma_{\mathcal{D}}^{P}+(1-\beta(1-\psi)) \psi \sigma_{\mathcal{A}}^{P}}{(1-\beta(1-2 \psi))(1-\beta)}(22) \\
W_{P}(\mathcal{A}) & =\frac{\psi y_{P}(\mathcal{D})+(1-\beta(1-2 \psi)-\psi) y_{P}(\mathcal{A})+\beta \psi^{2} \sigma_{\mathcal{A}}^{P}+(1-\beta(1-\psi)) \psi \sigma_{\mathcal{D}}^{P}}{(1-\beta(1-2 \psi))(1-\beta)}(.23)
\end{aligned}
$$

For given $\sigma_{\mathcal{D}}^{P}$ and $\sigma_{\mathcal{A}}^{P}$, substitution of this into equation (19) and rearranging give

$\mu \geq \frac{y_{P}(\mathcal{S})-y_{P}(\mathcal{D})}{1-\beta}-\frac{\beta \psi\left(y_{P}(\mathcal{A})-y_{P}(\mathcal{D})\right)+(1-\beta(1-\psi))^{2} \sigma_{\mathcal{D}}^{P}+\beta \psi(1-\beta(1-\psi)) \sigma_{\mathcal{A}}^{P}}{(1-\beta(1-2 \psi))(1-\beta)}$,

where we name the left-land side $\mu\left(\sigma_{\mathcal{D}}^{P}, \sigma_{\mathcal{A}}^{P}\right)$. This condition provides a necessary and sufficient condition for unconsolidated and consolidated democracy preventing a revolution. We need to derive condition (18). We need to find values of $\sigma_{\mathcal{D}}^{P}$ and $\sigma_{\mathcal{A}}^{P}$ such that permanent democracy, in expectation, is better than the expected value of unconsolidated democracy for the poor:

$$
\frac{y_{P}(\mathcal{D})}{1-\beta}+\sigma_{\mathcal{D}}^{P}>y_{P}(\mathcal{D})+\sigma_{\mathcal{D}}^{P}+\beta W_{P}(\mathcal{D})<=>\frac{y_{P}(\mathcal{D})}{1-\beta}>W_{P}(\mathcal{D}) .
$$

Substituting and rearranging, this can be expressed as in equation (18). The reason why we need this condition is that very large expected golden hellos give the poor a preference for unconsolidated democracy over consolidated democracy simply because each transition, in expectation, triggers a positive golden hello.

Is $\underline{\mu}\left(\sigma_{\mathcal{D}}^{P}, \sigma_{\mathcal{A}}^{P}\right)$ less that $\mu^{*}$ ? Suppose that $\sigma_{D}^{P}=\sigma_{A}^{P}=0$ and $y_{P}(\mathcal{D})=y_{P}(\mathcal{A})$. Then $\underline{\mu}=\mu^{*}$. Notice that

$$
\frac{\partial \underline{\mu}}{\partial y_{P}(\mathcal{D})}=\frac{-(1-\beta(1-\psi))}{(1-\beta(1-2 \psi))(1-\beta)}<0
$$

and that $\frac{\partial \underline{\mu}}{\partial \sigma_{\mathcal{D}}^{P}}<0$ and $\frac{\partial \underline{\mu}}{\partial \sigma_{\mathcal{A}}^{P}}<0$ while $\mu^{*}$ is not a function of $y_{P}(\mathcal{D}), \sigma_{\mathcal{A}}^{P}$, or $\sigma_{\mathcal{D}}^{P}$. Thus, $\underline{\mu}<\mu^{*}$ for all $y_{P}(\mathcal{D})>y_{P}(\mathcal{A}), \sigma_{\mathcal{A}}^{P} \geq 0$, and $\sigma_{\mathcal{D}}^{P} \geq 0$.

Deriving condition (5) We seek a condition that ensures that the rich will not share power with the poor in the absence of a threat of revolution (i.e., in social state $H$ or if $\left.\mu>\mu^{*}\right)$. The requires that the rich prefer perpetual autocracy to perpetual democracy (where the rich never attempt a coup after having given vote rights out and, in expectation, triggered a golden hello) and to unstable democracy (where the rich attempt a coup each time the state is $(L, \mathcal{A})$ for then to democratize the very next period). In perpetual autocracy each rich citizen gets $\frac{y_{R}(\mathcal{A})}{1-\beta}$ while in perpetual democracy each rich citizen expects to get $\frac{y_{R}(\mathcal{D})}{1-\beta}+\sigma_{\mathcal{D}}^{R}$. In unstable democracy each rich citizen expects to get

$$
\frac{y_{R}(\mathcal{D})+\psi \beta y_{R}(\mathcal{A})+(1-(1-\psi) \beta) \sigma_{\mathcal{D}}^{R}+\psi \beta\left(\sigma_{\mathcal{A}}^{R}-\phi\right)}{(1-\beta)(1+\psi \beta)} .
$$


As simple comparison between these payoffs shows that perpetual autocracy is preferred to the other regimes by the rich if condition (5) holds.

Proof of Proposition 1 The initial political state is $\mathcal{A}$. In autocracy, the poor move after the rich. In state $(H, \mathcal{A})$, the best response of the poor no matter what the rich do is not to organize a revolution. Anticipating that, the rich do not democratize. In state $(L, \mathcal{A})$, the poor organize a revolution if the rich do not democratize. Anticipating this, the best response of the rich is to democratize. In state $(H, \mathcal{D})$, the poor do not make any choice. The rich do not mount a coup because the cost of doing so is infinite. In state $(L, \mathcal{D})$, the poor do not make any choice. The rich will mount a coup if $\phi<\bar{\phi}$ and not mount one if $\phi>\bar{\phi}$. To complete the proof, we need to show that both cases are consistent with Assumption 6. Define the second argument of right-hand side of equation (5) as

$$
\bar{\sigma}_{\mathcal{D}}^{R}\left(\phi, \sigma_{\mathcal{A}}^{R}\right)=\frac{y_{R}(\mathcal{A})-y_{R}(\mathcal{D})}{1-(1-\psi) \beta}+\frac{\psi \beta\left(\phi-\sigma_{A}^{R}\right)}{1-(1-\psi) \beta}
$$

and rearrange $\phi=\bar{\phi}\left(\sigma_{\mathcal{A}}^{R}, \sigma_{\mathcal{D}}^{R}\right)$ as follows

$$
\underline{\sigma}_{\mathcal{D}}^{R}\left(\phi, \sigma_{\mathcal{A}}^{R}\right)=\frac{\left(\phi-\sigma_{\mathcal{A}}^{R}\right)(1-(1-\psi) \beta)}{\psi \beta}-\frac{y_{R}(\mathcal{A})-y_{R}(\mathcal{D})}{\beta \psi} .
$$

We notice $\bar{\sigma}_{\mathcal{D}}^{R}\left(\phi, \sigma_{\mathcal{A}}^{R}\right)$ and $\underline{\sigma}_{\mathcal{D}}^{R}\left(\phi, \sigma_{\mathcal{A}}^{R}\right)$ are (linearly) increasing in $\phi$ and that there exists a unique $\widetilde{\phi}=\frac{y_{R}(\mathcal{A})-y_{R}(\mathcal{D})}{1-\beta}+\sigma_{A}^{R}$ such that

$$
\frac{y_{R}(\mathcal{A})-y_{R}(\mathcal{D})}{1-\beta}=\bar{\sigma}_{\mathcal{D}}^{R}\left(\widetilde{\phi}, \sigma_{\mathcal{A}}\right)=\underline{\sigma}_{\mathcal{D}}^{R}\left(\widetilde{\phi}, \sigma_{\mathcal{A}}\right)
$$

Moreover, at $\phi=0, \underline{\sigma}_{\mathcal{D}}^{R}\left(0, \sigma_{\mathcal{A}}\right)<\bar{\sigma}_{\mathcal{D}}^{R}\left(0, \sigma_{\mathcal{A}}\right)$. This implies that for $\phi \in[0, \widetilde{\phi})$ there exist values of $\sigma_{\mathcal{D}}^{R}$ such that $\sigma_{\mathcal{D}}^{R}<\bar{\sigma}_{\mathcal{D}}^{R}\left(\phi, \sigma_{\mathcal{A}}^{R}\right)$ and $\sigma_{\mathcal{D}}^{R}>\underline{\sigma}_{\mathcal{D}}^{R}\left(\phi, \sigma_{\mathcal{A}}^{R}\right)$ and that there exist values of $\sigma_{\mathcal{D}}^{R}$ such that $\sigma_{\mathcal{D}}^{R}<\underline{\sigma}_{\mathcal{D}}^{R}\left(\phi, \sigma_{\mathcal{A}}^{R}\right)<\bar{\sigma}_{\mathcal{D}}^{R}\left(\phi, \sigma_{\mathcal{A}}^{R}\right)$. We can derive the equilibrium characterization for the case with unanticipated golden hellos by setting $\sigma_{\mathcal{A}}^{R}=\sigma_{\mathcal{D}}^{R}=$ $\sigma_{\mathcal{A}}^{P}=\sigma_{\mathcal{D}}^{P}=0$ and noting that we do not need to be concerned with consistency with Assumption 6 . 